\title{
Role of Type IV Pili in Virulence of Pseudomonas syringae pv. tabaci 6605: Correlation of Motility, Multidrug Resistance, and HR-Inducing Activity on a Nonhost Plant
}

\author{
Fumiko Taguchi and Yuki Ichinose \\ Graduate School of Natural Science and Technology, Okayama University, Tsushima-naka 1-1-1, Kita-ku, Okayama 700-8530 \\ Japan
}

Submitted 3 February 2011. Accepted 11 May 2011.

\begin{abstract}
To investigate the role of type IV pili in the virulence of phytopathogenic bacteria, four mutant strains for pilus biogenesis-related genes were generated in Pseudomonas syringae pv. tabaci 6605. PilA encodes the pilin protein as a major subunit of type IV pili, and the pilO product is reported to be required for pilus assembly. The fim $U$ and fim $T$ genes are predicted to produce minor pilins. Western blot analysis revealed that pilA, pilO, and fimU mutants but not the fimT mutant failed to construct type IV pili. Although the swimming motility of all mutant strains was not impaired in liquid medium, they showed remarkably reduced motilities on semisolid agar medium, suggesting that type IV pili are required for surface motilities. Virulence toward host tobacco plants and hypersensitive responseinducing ability in nonhost Arabidopsis leaves of pilA, pilO, and fim $U$ mutant strains were reduced. These results might be a consequence of reduced expression of type III secretion system-related genes in the mutant strains. Further, all mutant strains showed enhanced expression of resistancenodulation-division family members mexA, mexB, and $o p r M$, and higher tolerance to antimicrobial compounds. These results indicate that type IV pili are an important virulence factor of this pathogen.
\end{abstract}

Pseudomonas syringae pv. tabaci 6605 is a phytopathogenic bacterial isolate that causes wildfire disease on host tobacco plants and hypersensitive response (HR) on nonhost plants. Previously, we revealed that the polar flagella of this bacterium are essential for virulence in tobacco infection, and that a major component of the flagellin protein (FliC) of flagellar filaments induces HR in nonhost plants (Ichinose et al. 2003; Shimizu et al. 2003). We also found that the flagellin of this pathogen is a glycoprotein and that glycosylation is required for swimming and swarming motility, stabilization of the filament structure, and total virulence in tobacco plants (Taguchi et al. 2003a and b, 2006b, 2008; Takeuchi et al. 2003).

Pili are thin, flexible fibers, several micrometers long, that extend as bundles. It is known that type IV pili (TFP), extra-

Corresponding author: Y. Ichinose; Telephone and Fax: (+81) 862518308 ; E-mail: yuki@cc.okayama-u.ac.jp

* The $\boldsymbol{e}$-Xtra logo stands for "electronic extra" and indicates that three supplementary figures are published online. cellular appendages like flagella, are involved in the bacterial locomotion known as twitching motility, which is reported to be a flagellum-independent bacterial motion (Giltner et al. 2010; Mattick 2002). Further, TFP have been reported to be important for virulence in several animal pathogens such as $P$. aeruginosa and Neisseria gonorrhoeae (Proft and Baker 2009). TFP have been observed in a large variety of gramnegative bacteria and several gram-positive bacteria. TFP are also involved in attachment to host cells, biofilm formation, cell aggregation, phage transduction, and DNA uptake. Thus, TFP are thought to be an important organ for primary interaction with the host surface (Pelicic 2008; Proft and Baker 2009). TFP subunits, pilins, are synthesized as precursors (prepilins) with a hydrophilic leader peptide, which is cleaved by a leader peptidase encoded by the pilD gene (Strom et al. 1993). PilD peptidase is also responsible for methylation of $\mathrm{N}$ terminal phenylalanine (Strom et al. 1993). TFP can be classified into two groups, type IVa and type IVb, based on the lengths of the mature protein and leader peptide in the prepilin. Type IVa pilins possess a short leader peptide (less than 10 residues) and a peptide that is 150 to 160 residues long, whereas type IVb pilins have a long leader peptide (15 to 30 residues) and are either long (180 to 200 residues) or very short (40 to 50 residues) (Proft and Baker 2009).

TFP are polymers of major subunit pilins, which are pilA gene products, and some minor subunit pilins. The N-terminal part (20 to 35 residues) of mature pilin proteins, which are highly homologous, is extremely hydrophobic (Pelicic 2008; Proft and Baker 2009). In P. aeruginosa, over 50 genes located in unlinked regions are required for the biogenesis, assembly, and regulation of functional pili. Previous studies have reported that pilin-like proteins, termed minor pilins, such as FimU, PilV, PilW, PilX, and PilE, are essential for pilus biogenesis and that some minor pilins are incorporated into the filament and play a role in the initiation of pilus assembly in $P$. aeruginosa (Giltner et al. 2010; Pelicic 2008).

Although the role of TFP in animal-pathogenic bacteria has been investigated as described above, studies in plantpathogenic bacteria have been limited. In P. syringae pv. phaseolicola, Romantschuk and Bamford (1986) reported that nonpiliated bacterial strains showed much lower adherence to the leaf surface than strains expressing TFP. Piliated bacteria attached to the leaf surface at the site of stomata, whereas nonpiliated bacteria were evenly distributed on the leaf surface. They also found that, although both piliated and nonpiliated bacterial strains caused halo blight if injected 
into the plant, only piliated bacteria caused symptoms by a spray inoculation method. Thus, TFP are thought to be important for the initial adherence of bacteria at the stomata and are required for virulence (Romantschuk and Bamford 1986). In $P$. syringae pv. tomato DC3000, nonpiliated mutant strains pilA and pilD caused bacterial speck symptoms comparable with those produced by the wild-type (WT) strain by infiltration inoculation (Roine et al. 1998). However, the leaf surface-associated population sizes of nonpiliated mutants were significantly lower than those of the WT strain (Roine et al. 1998). These reports suggest that TFP may play a role in epiphytic fitness during foliar colonization. However, the mutant strain for fimA, a gene for the pilin protein in TFP of Xanthomonas campestris pv. vesicatoria, was not significantly reduced in virulence or adhesiveness to tomato leaves (Ojanen-Reuhs et al. 1997). Thus, detailed behavior of the TFP mutant strains is still obscure.

In this study, we generated mutant strains of the pilus biogenesis-related genes pilA, pilO, fimU, and fimT in P. syringae pv. tabaci 6605 and investigated their motilities, biofilm formation, and virulence toward the host tobacco plant. PilA encodes the pilin protein as a major subunit of TFP (Roine et al. 1998), and the pilO product is reported to be required for pilus assembly in Xylella fastidiosa (Li et al. 2007). The Pseudomonas Genome Database V2 predicts that the fimU and fimT genes produce minor pilins. Further, we investigated the production of acylhomoserine lactones (AHL), quorum-sensing signal molecules, and the antimicrobial tolerance of pilus-related mutant strains because flagellar motility-defective mutant strains such as $\triangle f l i C$ showed reduced production of AHL, and mutant strains defective in AHL production had increased expression of multidrug resistance-related genes such as mexE, $\operatorname{mexF}$, and $\operatorname{opr} N$, and showed increased tolerance to antibiotics (Taguchi et al. 2010a and b). We also demonstrated that pilusrelated mutant strains had reduced ability to induce HR in the nonhost Arabidopsis thaliana. Based on these results, we dis- cuss a possible correlation between multiple virulence factors and TFP expression.

\section{RESULTS}

\section{Organization of pilus-related genes and similarity of pilin proteins.}

Polymerase chain reaction (PCR) cloning successfully isolated the corresponding regions for pilA, pilO, fimU, and fimT (Fig. 1) from the genomic DNA of $P$. syringae pv. tabaci 6605. The deduced amino acid sequences of PilA, FimU, and FimT possess short leader peptides and a total of 131 to 168 residues with a conserved $\mathrm{N}$-terminal hydrophobic sequence (Fig. 1D), suggesting that these proteins are type IVa pilins. The deduced PilO protein has 207 amino acid residues with a molecular mass of $23.2 \mathrm{kDa}$, and showed $100 \%$ identity $(99.2 \%$ similarity in nucleotide sequence) with that of $P$. syringae pv. phaseolicola 1448A (data not shown).

\section{Bacterial growth and detection of PilA pilin protein.}

The four mutants pilA, pilO, fimU, and fimT and corresponding complemented strains were able to grow at the same growth rates as the WT strain in King's B (KB) medium (data not shown). To examine the effect of each mutation on pilus biogenesis in each mutant, mutant strains were grown in $\mathrm{KB}$ plates for $24 \mathrm{~h}$ at $27^{\circ} \mathrm{C}$; then, whole-cell lysates were subjected to sodium dodecyl sulfate polyacrylamide gel electrophoresis (SDS-PAGE), and PilA pilin protein was detected by Western blotting with an anti-PilA-specific antibody. As expected, PilA protein was not detected in the whole-cell lysates from the pilA mutant strain, whereas PilA was detected in all other strains, including other mutant strains (data not shown). On the other hand, PilA proteins were detected in the pilus-containing surface fractions from WT, the fimT mutant strain, and all complemented strains by Western blotting with the PilA antibody (Fig. 2). Unlike the case of whole-cell lysates, PilA pilin
A
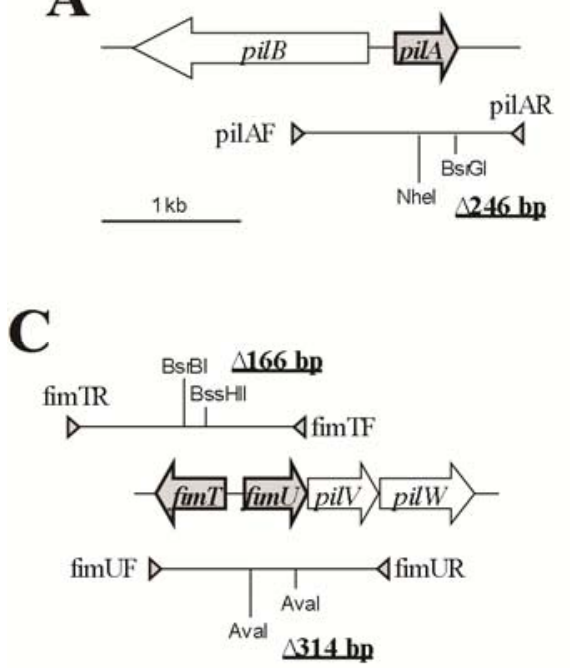

B
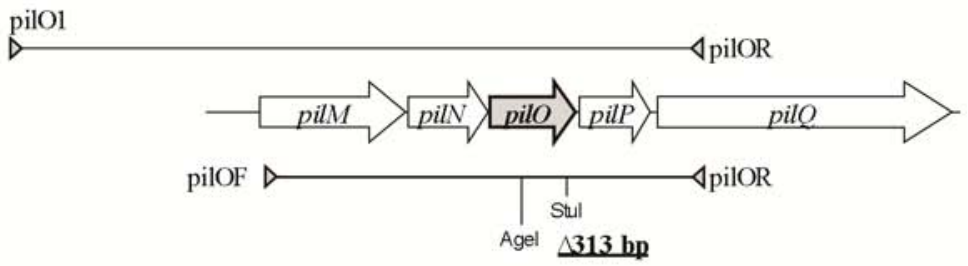

D

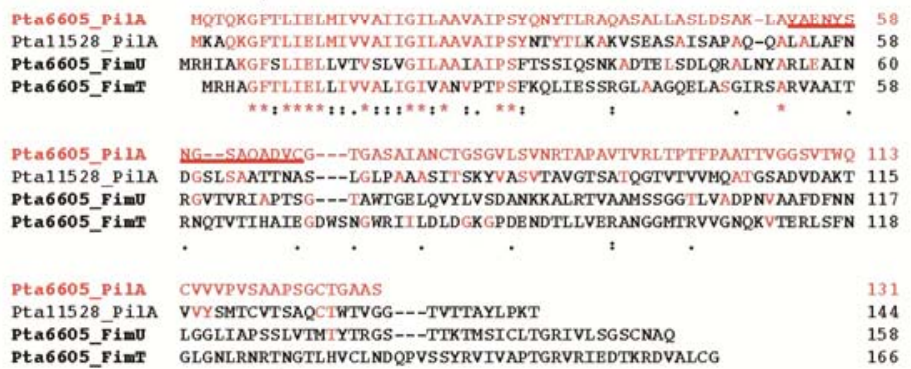

Fig. 1. Schematic organization of pilus biogenesis-related genes in Pseudomonas syringae pv. phaseolicola 1448A and construction of the pilA, pilO, fimU, and fimT mutants in the corresponding regions of $P$. syringae pv. tabaci 6605. Genetic regions containing $\mathbf{A}$, pilA; $\mathbf{B}$, pilO; and $\mathbf{C}$, fimU and fimT are shown. Primers used for polymerase chain reaction are indicated by arrowheads. To generate the internal deletion, digestion was performed with $N h e I$ and $B s r$ GI for pilA, AgeI and StuI for pilO, AvaI for fimU, and Bss HII and BsrBI for fimT. The sizes of deleted DNA fragments are also shown. D, Multiple sequence alignment of deduced amino acid sequences of PilA, FimU, and FimT from P. syringae pv. tabaci 6605 and PilA from P. syringae pv. tabaci ATCC 11528 (accession number: ZP_05638044). Conserved amino acids are denoted by asterisks. The peptide sequence (VAENYSNGSAQADVC) that was used as an antigen to generate the anti-PilA-specific antibody is underlined. The closed triangle indicates the putative methylphenylalanine of the N-terminal residue of the mature pilin protein. Locus ID numbers of pilA, pilO, fumU, and fimT in P. syringae pv. phaseolicola are PSPPH_0821, PSPPH_0392, PSPPH_0726, and PSPPH_0725, respectively. 
was detected in neither pilO and fim $U$ mutant strains nor the pilA mutant.

\section{Motility experiments.}

To investigate the role of TFP in the motility of $P$. syringae pv. tabaci 6605 on semisolid surfaces, swimming motility on a $0.25 \%$ agar MMMF plate and swarming motility on a $0.5 \%$ agar SWM plate of the mutant and complemented strains (pilA-C, pilO-C, fimU-C, and fimT-C) were compared with those of the WT strain. All mutant strains had remarkably reduced surface swimming motility, and this motility was partially restored in all complemented strains (Fig. 3A). The surface swarming motility was also impaired in all mutant strains: the pilA, pilO, and fimU mutant strains showed no swarming motility within $48 \mathrm{~h}$ and after prolonged incubation to $96 \mathrm{~h}$ under this experimental condition, while the fimT mutant retained a weak but significant level of swarming motility even after $48 \mathrm{~h}$ of incubation, and spread across the whole surface after 72 and 96 h of incubation (Fig. 3B; Supplementary Fig. S1A). All complemented strains had swarming motility at the WT level. Quantitative analyses of swimming and swarming

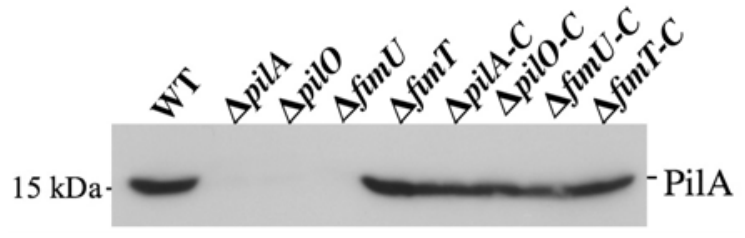

Fig. 2. Detection of PilA protein. Pilus-containing surface fractions from the wild type (WT), each mutant, and complemented strains were separated on a $15 \%$ sodium dodecyl sulfate polyacrylamide gel electrophoresis gel and analyzed with anti-PilA-specific antibody. Each bacterium strain was incubated in King's B medium plates at $27^{\circ} \mathrm{C}$. pilA-C, pilO-C, fimU-C, and fim $T$-C indicate each respective complemented strain. The photographs show representative results obtained from three independent experiments.
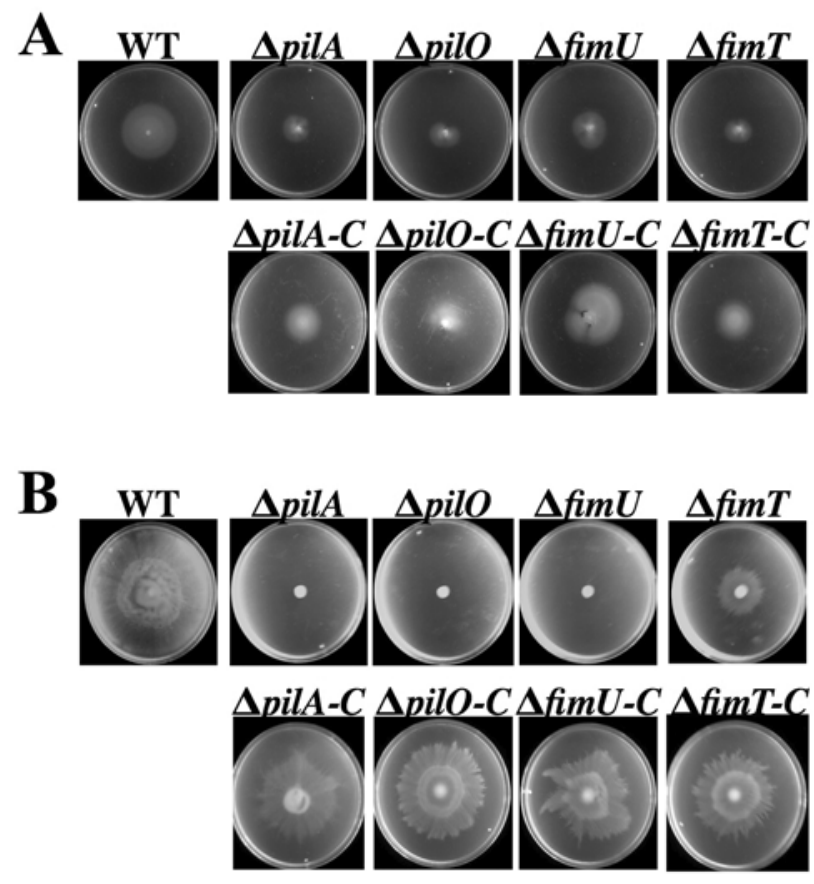

Fig. 3. Motility experiments. A, Surface swimming motility (MMMF with $0.25 \%$ agar) at $25^{\circ} \mathrm{C}$ and $\mathbf{B}$, surface swarming motility (SWM with $0.5 \%$ agar) at $27^{\circ} \mathrm{C}$ of the wild type (WT), each mutant, and complemented strain were examined. Plates were incubated for 48 h. pilA-C, pilO-C, fimU-C, and fim $T$-C indicate each respective complemented strain. The photographs show representative results obtained from three independent experiments. motilities are summarized in Table 1 . From these results, the pilA, pilO, and fim $U$ mutant strains were thought to lose swarming motility while the fimT mutant strain had reduced motility. Previously, we reported that these movements depend on flagellar motility because the $\Delta f l i C$ mutant was unable to spread on a semisolid agar surface $(<0.5 \%)$ (Shimizu et al. 2003; Taguchi et al. 2006b). It is notable that there was no difference between the WT and each pilus-related mutant strain in swimming motility in MMMF liquid medium (data not shown). These results indicated that the flagellum is the dominant organelle for both swimming and swarming motilities and that pili are required for these surface motilities.

Twitching motility is well recognized as typical movement of TFP in many bacteria (Giltner et al. 2010; Pelicic 2008; Proft and Baker 2009). We investigated the twitching motilities of WT and TFP-related mutant strains with two methods: visualization after a 48 -h incubation at the bottom of $1 \%$ agar $\mathrm{KB}$ plates, often used in animal bacteria; and assessment by colony morphology, used in plant-pathogenic bacteria. Interestingly, the WT strain and all TFP-related mutant strains of $P$. syringae pv. tabaci 6605 weakly spread at the bottom of the medium, and showed the same colony morphology; there were no significant differences in twitching motilities among the strains tested.

\section{Virulence of mutants on host tobacco leaves.}

The virulence of the WT and TFP-related mutant strains on host tobacco leaves was examined by both the dip-inoculation method (Fig. 4) and infiltration method (Supplementary Fig. S2). In dip inoculation, the pilA, pilO, and fimU mutant strains were less virulent than the WT strain, while the fimT mutant retained a significant level but weaker virulence than the WT strain, and all complemented strains had completely restored ability to cause disease symptoms (Fig. 4A). Furthermore, bacterial populations of all mutant strains had less growth than the WT strain on host tobacco leaves, and all complemented strains restored WT-level propagation (Fig. 4B). We also assessed differences in virulence of the WT and mutant strains by the infiltration method. Differences between WT and TFPrelated mutant strains in severity of disease symptoms were not obvious in the infiltrated leaves, although symptom development by inoculation with the TFP-related mutant was smaller than that with the WT strain, and bacterial populations of TFP-related mutant strains were significantly lower than that of the WT strain. These results demonstrated that the type IVa pilus in $P$. syringae pv. tabaci 6605 is an important virulence factor in host tobacco infection.

\section{Biofilm formation.}

Because TFP are thought to be involved in biofilm formation and attachment to the host surface (Bahar et al. 2009; Li et

Table 1. Quantitative analysis of surface motility

\begin{tabular}{|c|c|c|}
\hline \multirow[b]{2}{*}{ Strains } & \multicolumn{2}{|c|}{ Motility $(\mathrm{cm})^{\mathbf{a}}$} \\
\hline & Swimming & Swarming \\
\hline WT & $3.13 \pm 0.210$ & $6.17 \pm 0.153$ \\
\hline pilA & $0.50 \pm 0.082 *$ & $0.80 \pm 0.100 * \dagger$ \\
\hline pilO & $0.75 \pm 0.173 *$ & $0.83 \pm 0.115 * \dagger$ \\
\hline fimU & $0.65 \pm 0.141 *$ & $0.76 \pm 0.058 * \dagger$ \\
\hline fimT & $0.80 \pm 0.095^{*}$ & $2.63 \pm 0.153 *$ \\
\hline pilA-C & $2.01 \pm 0.126$ & $4.93 \pm 0.116$ \\
\hline pilo-C & $1.93 \pm 0.372$ & $5.20 \pm 0.300$ \\
\hline fimU-C & $2.35 \pm 0.096$ & $5.13 \pm 0.115$ \\
\hline fimT-C & $2.23 \pm 0.175$ & $5.33 \pm 0.153$ \\
\hline
\end{tabular}

a Symbols indicate a significant difference from the motility of the wild type (WT) in one-way analysis of variance (* indicates WT vs., $P<0.05$, and $\dagger$ indicates fimT vs., $P<0.05$ ). Data shown are the average of three independent replicates. 
al. 2007), the ability of each TFP-related mutant strain to form a biofilm was compared with that of the WT strain. Quantitative analysis of the adherent cells revealed that the pilA, pilO, and fim $U$ mutant strains had reduced ability to attach to a polystyrene surface with a statistically significant difference but the fim $T$ mutant strains retained the ability to form a biofilm at the WT level (Fig. 5). Reduction of biofilm formation activity was prominent in the pilA and pilO mutant strains, and there were also significant differences in biofilm formation between the fimT mutant and the pilA and pilO mutant strains. All complemented strains had restored ability to form a biofilm.

\section{AHL production and antibiotic tolerance.}

Because we previously found that motility-defective mutants such as the $\Delta f l i C$ mutant strain had enhanced antibiotic tolerance (Taguchi et al. 2010b), the tolerance of TFP-related mutant strains was examined. Minimum inhibitory concentration (MIC) tests for chloramphenicol, cefotaxime, ampicillin, spectinomycin, tetracycline, crystal violet, and SDS revealed remarkably increased tolerance to these antimicrobial compounds in all TFP-related mutant strains (Table 2). It is known that AHL production-defective mutant strains such as $\Delta f l i C$ and psyI highly express the genes encoding MexE, MexF, and OprN, members of the resistance-nodulation-division (RND) pump family (Taguchi et al. 2010a and b). Therefore, the abilities of AHL production in the WT and TFP-related mutant strains were compared using Chromobacterium violaceum CV026 as the AHL biosensor strain. However, all TFP-related mutant strains were able to produce WT levels of AHL (Supplementary Fig. S3), indicating that the enhanced tolerance of pilus-related mutant strains to antimicrobial compounds is not mediated by a quorum-sensing system via AHL production. To investigate the reason for the enhanced tolerance to antimicrobial compounds, we carried out microarray analysis and found that expressions of mexA, mexB, and oprM (genes of another RND pump family member) and the $t \operatorname{tg} R$ gene were significantly upregulated in all TFP-related mutant strains (Fig. 6A). MexAB-OprM is known as a major multidrug efflux system in $P$. syringae (Stoitsova et al. 2008). The $t \operatorname{tg} R$ gene product is reported to be a transcriptional repressor for binding of natural antimicrobial compounds in $P$. putida DOT-TIE, which are transported via a multidrug efflux pump (Alguel et al. 2007; Terán et al. 2006). Enhanced expression of mexB and oprM genes in TFP-related mutant strains was also confirmed by real-time reverse-transcription (RT)-PCR analysis (Fig. 6C).

\section{HR-inducing activity in a nonhost plant.}

Microarray analysis also revealed that all TFP-related mutant strains had reduced expression of many hrp-related genes and $v f r$ and $c y a A$ genes (Fig. 6B). The $v f r$ and $c y a A$ genes encode cAMP-binding protein $\mathrm{Vfr}$ and adenylate cyclase, a cAMP biosynthetic enzyme, respectively. The hrp-related genes include genes for the Hrp type III secretion apparatus,

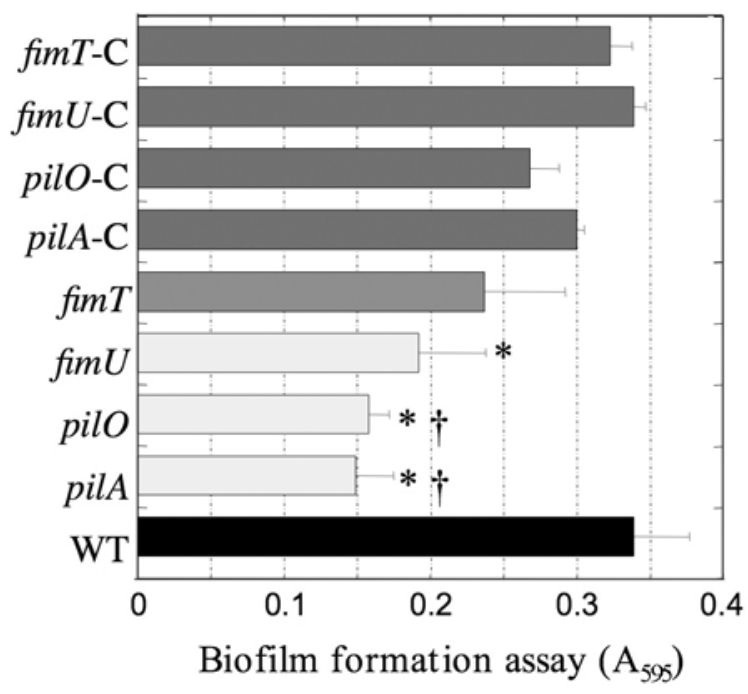

Fig. 5. Biofilm formation by the wild type (WT), each mutant, and complemented strains. Each bacterium was grown in Luria-Bertani medium with $10 \mathrm{mM} \mathrm{MgCl} 2$, transferred to fresh MMMF medium, and incubated for $48 \mathrm{~h}$ at $25^{\circ} \mathrm{C}$ without agitation. Adherent bacteria were stained with $0.5 \%$ crystal violet and washed with water. After destaining with $95 \%$ ethanol, optical density at $595 \mathrm{~nm}$ values were measured. Averages obtained from three independent experiments are shown. Symbols indicate a significant difference from the WT or $\operatorname{fim} T$ (* indicates WT vs., $P<0.05$, and $\dagger$ indicates fimT vs., $P<0.05)$.
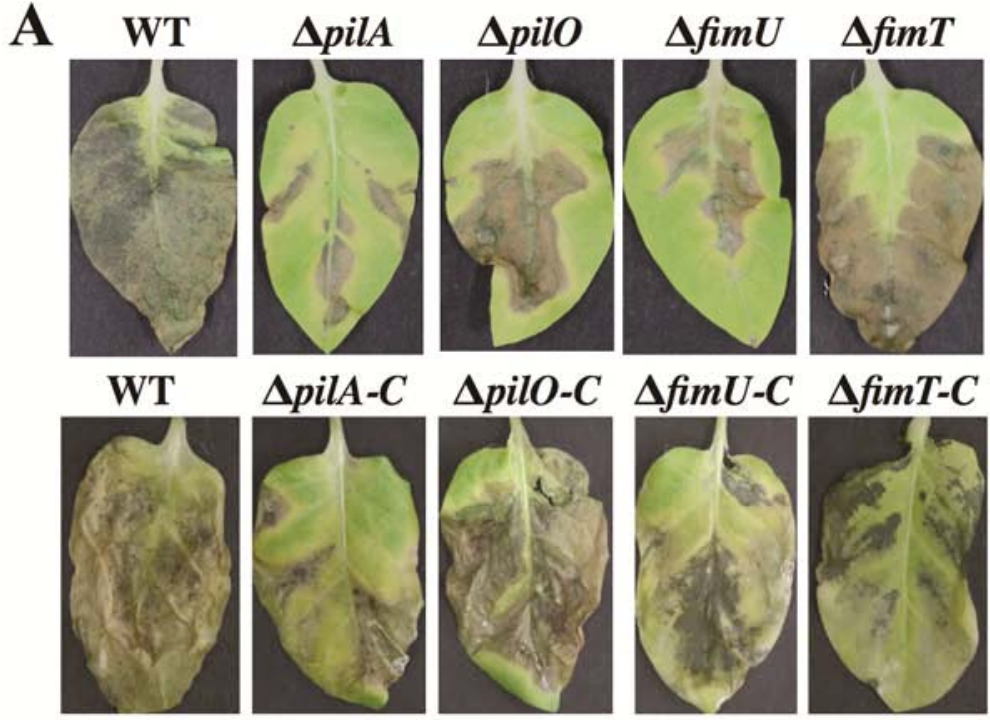

Fig. 4. Inoculation tests. A, Tobacco leaves were inoculated with the wild type (WT), each mutant, and complemented strains by the dip-inoculation method at $2 \times 10^{8} \mathrm{CFU} / \mathrm{ml}$ and were incubated at $23^{\circ} \mathrm{C}$. Photographs taken 12 days after inoculation show representative results obtained from three independent experiments. B, Bacterial growth in tobacco leaf disks dip inoculated at $2 \times 10^{8} \mathrm{CFU} / \mathrm{ml}$ was measured at 1,3 , and 6 days post inoculation. Bars represent standard deviations for three independent experiments. Asterisks $(*)$ indicate a significant difference from the populations of the WT $(P<0.05)$. 
Hrp effectors, and Hrp chaperone proteins. Quantitative realtime RT-PCR analysis confirmed that the expression of the $h r p A$ and $h r p K$ genes of all mutant strains was weaker than that of the WT strain in a nutrient-poor medium (Fig. 6C). Because $h r p$ genes are also involved in induced defense responses in nonhost plants, defense responses of $A$. thaliana were investigated after inoculation with the WT and TFP-related mutant strains of $P$. syringae pv. tabaci 6605 . The results clearly showed that the WT strain induced HR with rapid death of the host cells, while inoculation with pilO and fimU mutant strains caused only weak chlorosis-like changes and the pilA mutant did not induce a clear change. Furthermore, we observed that three mutant strains-pilA, pilO, and fimU - had reduced ability to induce callose deposition in Arabidopsis leaves (Fig.
7B). These results suggested that the TFP of this pathogen is required for HR induction in nonhost $A$. thaliana. Finally, the survival of the TFP-related mutant strains in nonhost Arabidopsis was analyzed (Fig. 7C). Although the number of pilA mutant was reduced at 1 day after inoculation, the pilA mutant was somewhat multiplied at 6 days after inoculation. This result might be related to the impaired $\mathrm{HR}$ in pilA-inoculated leaves and reduced expression of hrp-related genes in TFPrelated mutant strains.

\section{DISCUSSION}

Previous studies identified pilin-like proteins with conserved $\mathrm{N}$-terminal sequences, termed minor pilins, which are thought

Table 2. Antimicrobial susceptibility of the wild type (WT) and pilus-related mutants from Pseudomonas syringae pv. tabaci 6605

\begin{tabular}{|c|c|c|c|c|c|c|c|}
\hline \multirow[b]{2}{*}{ Strains } & \multicolumn{7}{|c|}{ Minimum inhibitory concentration $(\mu \mathrm{g} / \mathrm{ml})$} \\
\hline & Chloramphenicol & Cefotaxime & Ampicillin & Spectinomycin & Tetracycline & Crystal violet & Sodium dodecyl sulfate \\
\hline WT & 6.25 & 6.25 & 100 & 6.25 & 0.78 & 25 & 2,000 \\
\hline pilA & 50 & 50 & 400 & 12.5 & 1.56 & 100 & 4,000 \\
\hline pilO & 50 & 50 & 400 & 12.5 & 1.56 & 100 & 4,000 \\
\hline fimU & 50 & 50 & 400 & 12.5 & 1.56 & 100 & 4,000 \\
\hline fimT & 25 & 50 & 400 & 12.5 & 1.56 & 100 & 4,000 \\
\hline
\end{tabular}

\begin{tabular}{|c|c|c|c|c|}
\hline & pilA & pilo & $f i m U$ & fim $T$ \\
\hline PSPPH_4012 (ttgR) & 228 & 2.71 & 2.04 & 1.70 \\
\hline PSPPH_4013 (mexA) & 1244 & 1243 & 1298 & 14.42 \\
\hline PSPPH_4014 (mexB) & 1428 & 15.30 & 20.15 & 15.92 \\
\hline PSPPH_4015 (oprM) & 9.17 & 6.73 & 1125 & 9.20 \\
\hline & pilA & pill & fim $U$ & fim $T$ \\
\hline PSPPH_1272 (hrpA2) & 0.17 & 0.14 & 0.34 & 0.14 \\
\hline PSPPH_1273 (hrpZI) & 0.19 & 0.18 & 0.31 & 0.18 \\
\hline PSPPH_1274 (hrpB) & 0.21 & 0.20 & 0.40 & 0.19 \\
\hline PSPPH_1278 (hrpF) & 0.23 & 0.19 & 0.36 & 0.21 \\
\hline PSPPH_1279 (hrpG) & 0.27 & 0.26 & 0.44 & 0.28 \\
\hline PSPPH_1265 (shoM) & 0.27 & 0.21 & 0.67 & 0.27 \\
\hline PSPPH_1289 (hro0) & 0.41 & 0.26 & 0.39 & 0.32 \\
\hline PSPPH_1296 (hopXI) & 0.27 & 0.29 & 0.50 & 0.24 \\
\hline PSPPH_1295 (hrpKI) & 0.33 & 0.32 & 0.73 & 0.27 \\
\hline PSPPH_0171 (hopRI) & 0.56 & 0.32 & 0.92 & 0.50 \\
\hline PSPPH_5227 (hrpT) & 0.30 & 0.35 & 0.54 & 0.32 \\
\hline PSPPH_1275 (hrcd) & 0.40 & 0.37 & 0.58 & 0.45 \\
\hline PSPPH_1267 (avrf) & 0.40 & 0.37 & 0.51 & 0.43 \\
\hline PSPPH_1288 (hrpP) & 0.50 & 0.38 & 0.63 & 0.51 \\
\hline PSPPH_1281 (hrpV) & 0.46 & 0.38 & 0.63 & 0.56 \\
\hline PSPPH_1286 (hrcQb) & 0.35 & 0.39 & 0.52 & 0.43 \\
\hline PSPPH_1280 (hrcC) & 0.38 & 0.42 & 0.62 & 0.32 \\
\hline PSPPH_1291 (hrpQ) & 0.39 & 0.48 & 0.63 & 0.43 \\
\hline PSPPH_1268 (avrEI) & 0.43 & 0.48 & 0.75 & 0.50 \\
\hline PSPPH_0626 (vfr) & 0.46 & 0.64 & 0.60 & 0.82 \\
\hline PSPPH_5013 (cyaA) & 0.55 & 0.84 & 0.48 & 0.61 \\
\hline
\end{tabular}
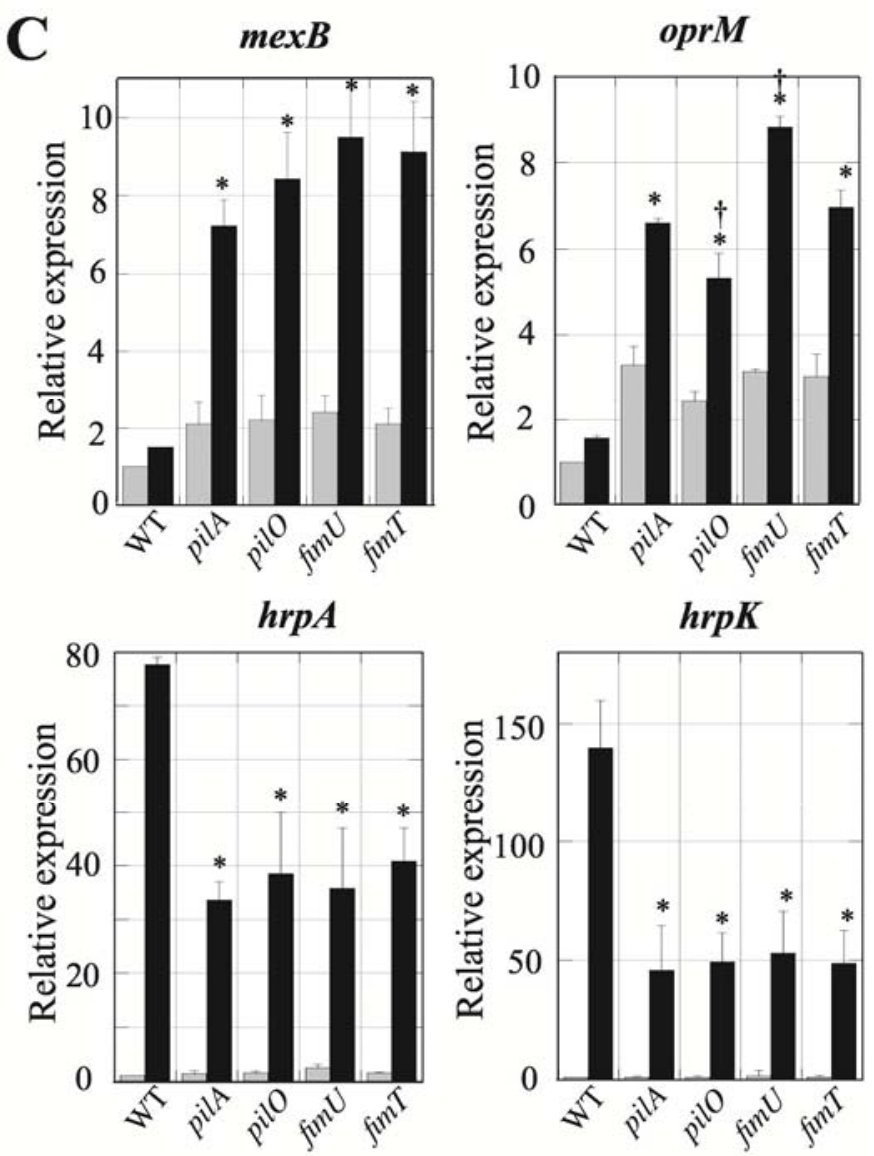

Fig. 6. Gene expression profiles of pilus-related mutant strains compared with those of the wild-type (WT) strain. Expression of A, multidrug resistancerelated genes and $\mathbf{B}$, type III secretion system-related genes and $v f r$ and cyaA genes by a microarray analysis. The fold-induction of upregulated genes in any of the type IV pili-related mutant strains, including multidrug resistance-related genes, are indicated by pale peach, mustard yellow, gold, and dark orange, while that of the downregulated genes, including many hrp-related genes and $v f r$ and $c y a A$ genes, are indicated by light blue, blue, and green-blue. C, Expression of the mexB, oprM, hrpA, and $h r p K$ genes in the WT and all mutant strains at $1 \mathrm{~h}$ after incubation in Luria-Bertani (LB) medium with $10 \mathrm{mM}$ $\mathrm{MgCl}_{2}$ (gray bars) or in MMMF medium (black bars). Quantitative real-time reverse-transcription polymerase chain reaction was carried out using total RNA prepared from each strain. The expression level of each gene was normalized to that of the rpoD gene and the relative value of WT expressed in LB medium with $10 \mathrm{mM} \mathrm{MgCl}$ was set to 1 as a control. Data are representative results obtained from three independent experiments. Symbols indicate a significant difference from the WT or fimT in MMMF medium (* indicates WT vs., $P<0.05$, and $\dagger$ indicates fim $T$ vs., $P<0.05$ ). 
to be essential to pilus assembly and twitching motility in $P$. aeruginosa (Giltner et al. 2010). It was reported that minor pilins encoded by fimU, pilV, pilW, pilX, and pilE in P. aeruginosa are incorporated into filaments of TFP and play a role in the initiation of pilus assembly (Giltner et al. 2010). PilN and $\mathrm{PilO}$ are also reported to form heterodimers and construct the foundation of the inner membrane complex of PilM/N/O/P (Ayers et al. 2009; Sampaleanu et al. 2009). This complex is essential for the assembly of functional TFP, and PilO is necessary for the proper folding of the PilM protein (Sampaleanu et al. 2009). In P. syringae pv. tabaci 6605, the deduced amino acid sequences of the pilA, fimU, and fim $T$ genes showed significant homology in the N-terminal region (Fig. 1D). As shown in the result of Western blotting with a PilA-specific antibody, not only the pilA mutant but also both pilO and fim $U$ mutants failed to manifest the PilA pilin protein in surface fractions containing pilus filaments (Fig. 2). The results indicated that PilA, PilO, and FimU but not FimT are indispensable for pilus assembly in P. syringae pv. tabaci 6605 .

We previously reported that the flagella-defective $\triangle f l i C \mathrm{mu}-$ tant lost both swimming motility in low-agar medium $(<0.3 \%)$ and swarming motility in $0.5 \%$ agar semisolid medium (Shimizu et al. 2003; Taguchi et al. 2006b), suggesting that these types of surface motilities are dependent on flagellar function. In this study, we demonstrated that TFP-related mutant strains were also impaired in these surface swimming and swarming motilities (Fig. 3). However, all TFP-related mutant strains retained the same level of swimming motility as the
WT in a liquid medium, indicating that swimming motility in a liquid medium is completely dependent on flagellar function but surface motility requires both flagella and TFP. Köhler and associates (2000) reported that $P$. aeruginosa required TFP for surface swarming motility but not for surface swimming motility. In this study, we found that the TFP-related mutant strains pilA, pilO, and fimU in $P$. syringae. pv. tabaci 6605 partially retained surface swimming motility but lost surface swarming motility, which indicates that the contribution of TFP is indispensable to the swarming motility but only supportive to the surface swimming motility. The degree of the contribution of flagella and TFP to swarming motility might be dependent on the bacterial species, strain, and culture conditions used in swarming assay.

Köhler and associates (2000) further demonstrated that the mutants defective for las and rhl cell-to-cell signaling systems and $r h l A$ rhamnolipid production had reduced swarming motility, which indicates that a cell-to-cell signaling circuitry is required for the surface swarming motility of $P$. aeruginosa. We also reported that swarming motility is linked to bacterial virulence and that biosurfactants that reduce surface tension increased swarming motility (Taguchi et al. 2006a and b, 2010a). Although the relationship between TFP and quorum sensing has not been adequately elucidated in $P$. syringae pv. tabaci 6605, all TFP-related mutant strains produced AHL at the WT level, suggesting that a regulatory network of TFP-mediated virulence factors might exist independently of the quorum sensing mediated by AHL in this bacterium.

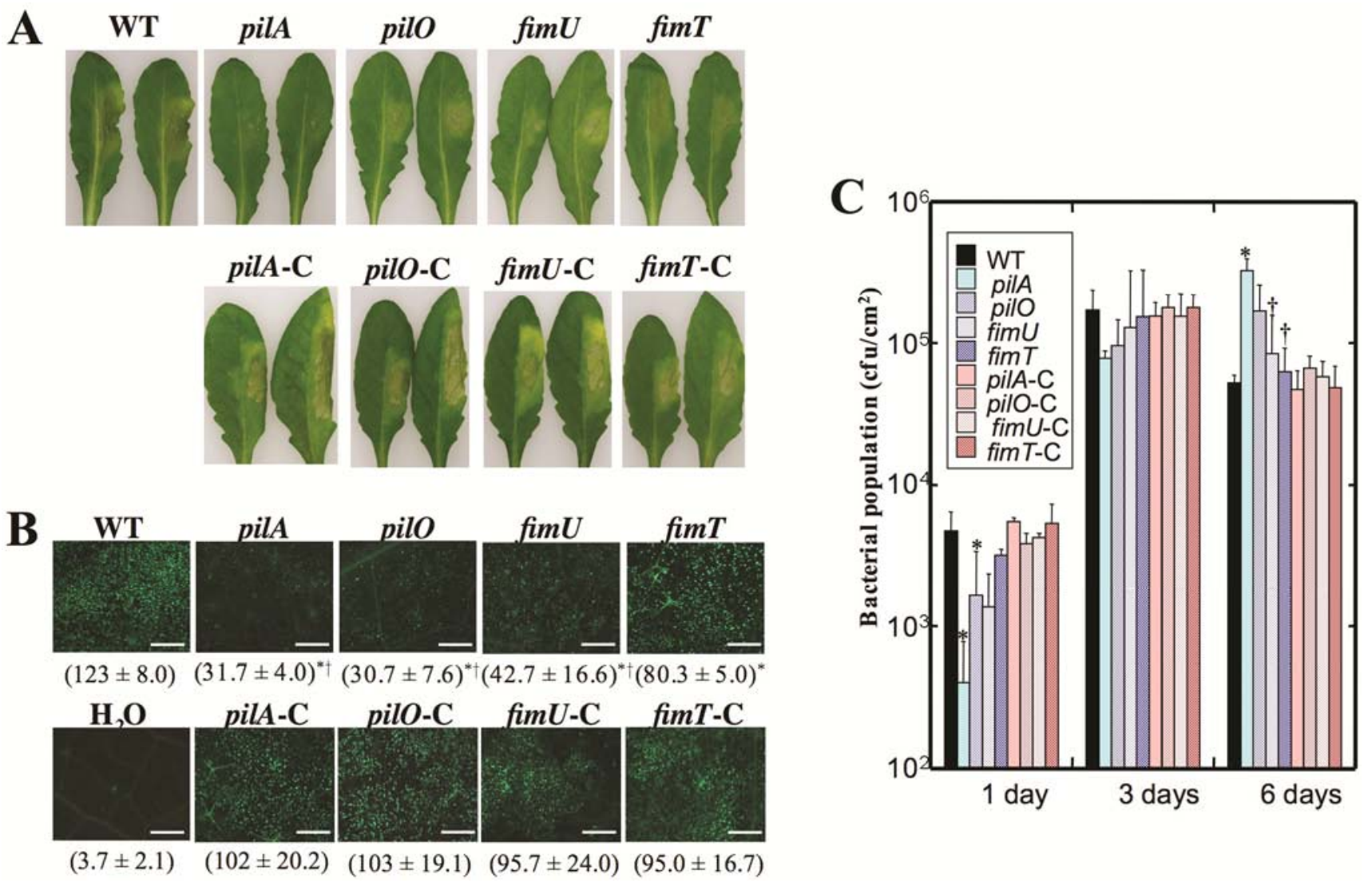

Fig. 7. Hypersensitive response-inducing ability and bacterial population in nonhost Arabidopsis thaliana. Arabidopsis leaves were inoculated with the wild type (WT), each mutant, and complemented strain at a density of $2 \times 10^{8} \mathrm{CFU} / \mathrm{ml}$, and incubated at $22^{\circ} \mathrm{C}$ with a $16-\mathrm{h}$ photoperiod for 2 days. A, Detection of cell death. Leaves were infiltration-inoculated with each bacterial strain. Photographs show representative results obtained from three independent experiments. B, Microscopic observation of callose deposition. Leaves were infiltration-inoculated with each bacterial strain. Average numbers with standard deviations (SD of callose deposits per 4- $\mathrm{mm}^{2}$ area from three independent experiments are shown in parentheses. Symbols indicate a significant difference from the WT or fimT (* indicates WT vs., $P<0.05$, and $\dagger$ indicates fimT vs., $P<0.05$ ). Scale bar is $500 \mu m$. C, Bacterial population of each strain. Leaves were dip-inoculated with each bacterial strain. Graph shows the means with SD from four independent experiments. Symbols indicate a significant difference from the WT or pilA (* indicates WT vs., $P<0.05$, and $\dagger$ indicates pilA vs., $P<0.05$ ). 
Among phytopathogenic bacteria, TFP have also been reported to play a critical role in surface attachment, biofilm formation, twitching motility, and virulence in Acidovorax avenae subsp. citrulli (Bahar et al. 2009, 2010) and Ralstonia solanacearum (Kang et al. 2002; Liu et al. 2001). A. avenae subsp. citrulli mutated for pilM and pilT genes, which encode a TFP-assembly protein and an ATPase for retraction of TFP, respectively, exhibited reduced twitching motility, biofilm formation, and virulence (Bahar et al. 2009). The pilA mutant strain in $R$. solanacearum did not exhibit twitching motility and showed reduced virulence on tomato plants and diminished auto-aggregation and biofilim formation (Kang et al. 2002). Furthermore, transposon mutagenesis in $X$. oryzae pv. oryzicola revealed that genes involved in TFP assembly and twitching motility are required for virulence (Wang et al. 2007). However, the role of TFP is different in gram-negative nonflagellated bacterium $X$. fastidiosa, because fimT and pilO mutant strains of this pathogen lacked TFP and produced more abundant biofilms than the WT strain (Li et al. 2007). Our study demonstrated that the TFP-related mutant strains of $P$. syringae pv. tabaci 6605 had reduced surface motility, biofilm formation, and virulence on its host tobacco plant in a dip-inoculation assay. Therefore, TFP generally seem to be required for bacterial attachment, biofilm formation, and virulence in most plant-pathogenic bacteria except $X$. fastidiosa.

Previous studies by Romantschuk and Bamford (1986) and Roine and associates (1998) also demonstrated that TFP are important in the early infection stage in $P$. syringae because TFP-defective mutant strains displayed only weak disease symptoms, and the epiphytic population of the TFP mutant strains was smaller than that of the WT strain. The differences in virulence evidenced by symptom severity and bacterial growth in planta between WT and TFP-related mutant strains of $P$. syringae pv. tabaci 6605 were not as obvious for the infiltration experiment as in the dip-inoculation experiment (Fig. 4), although the virulence of the mutant strains was still lower than that of the WT strain. The lower expression of hrp-related genes in the mutant strains is probably part of the reason for this phenomenon.

It should be noted that the fimT mutant strain had reduced surface motility (Fig. 3) and virulence (Fig. 4) and showed a gene expression profile similar to those of other TFP-related mutant strains (Fig. 6). However, PilA assembly (Fig. 2) and biofilm formation (Fig. 5) in the fimT mutant was similar to that of the WT strain. These results suggest that TFP in the fim $T$ mutant are not fully functional, and fimT mutation definitively affected bacterial function, including surface motility, gene expression, and virulence.

Although it has been reported for both animal bacteria and plant bacteria that TFP are required for "twitching motility", the assay methods for twitching motility differ. In animalpathogenic bacteria such as $P$. aeruginosa, twitching motility has been examined at the bottom of nutrient-rich $1 \%$ agar plates after stab inoculation with a sterile toothpick (Giltner et al. 2010), and a similar method was used in Escherichia coli (Mazariego-Espinosa et al. 2010). However, twitching mobility in plant-pathogenic bacteria has often been investigated by naked-eye and light microscopic observations of colony morphology, as described below. In A. avenae subsp. citrulli, twitching motility was confirmed by the formation of a thin, light halo around the bulk colony on the plate (Bahar et al. 2009, 2010 ) and, in $R$. solanacearum, twitching motility was examined by colony morphology as seen by an upright light microscope (Kang et al. 2002; Liu et al. 2001). Furthermore, it has also been reported that twitching-negative mutants have a smooth colony margin (e.g., there was no twitching-associated peripheral fringe in X. fastidiosa) (Li et al. 2007; Meng et al.
2005). In this study, we found that both animal bacteria-type and plant bacteria-type "twitching motilities" were not affected by the mutation of TFP-related genes in $P$. syringae pv. tabaci 6605. Because pilA, pilO, and fim $U$ mutant strains did not assemble pilus filaments (Fig. 2) and lost surface swarming motility (Fig. 3), swarming motility is a representative TFPmediated motility in this pathogen.

$\mathrm{HR}$, a rapid and localized plant defense response to plant pathogens, is induced by the inoculation of incompatible host pathogens or nonhost pathogens (Jin et al. 2003). It is known that an hrp gene cluster is required for HR in nonhost plants and pathogenicity in host plants. Thus, the disruption of the hrp locus results in the loss of HR in its nonhost plants (Lindgren et al. 1986). In this study, we found that TFP-related mutant strains of $P$. syringae pv. tabaci 6605 had decreased expression of hrp-related genes; consequently, HR-inducing activity was reduced in nonhost Arabidopsis leaves (Figs. 6 and 7). In $P$. aeruginosa, it was reported that the expression of type III secretion system (T3SS)-related genes was induced by bacterial contact with host cells via TFP (Yahr and Wolfgang 2006). Thus, TFP seem to relate to the expression of T3SS genes. However, it is not understood yet how expression of T3SS genes is related to TFP. In $P$. aeruginosa, it was reported that the expression of T3SS genes accompanies an increase of intracellular cAMP levels, and a host cell contact signal activates the expression of T3SS genes through the cAMP pathway (Wolfgang et al. 2003; Yahr and Wolfgang 2006). It was also reported that, in a cAMP synthesis-defective mutant, expression of the $v f r$ gene was reduced to half, and the Vfr protein level was also reduced to one tenth (Wolfgang et al. 2003; Yahr and Wolfgang 2006). Vfr is a cAMP-binding protein and a global regulator of many virulence factors, including toxin production, quorum sensing, flagellar biosynthesis, TFP biogenesis, and expression of T3SS-related genes (Whitchurch et al. 2005). Therefore, sufficient cAMP and subsequent accumulation of $\mathrm{Vfr}$ protein seem to be necessary for enhanced expression of T3SS genes. The expression of $v f r$ and $c y a A$ genes was significantly reduced in pilA, pilO, and fim $U$ mutants in $P$. syringae pv. tabaci 6605 (Fig. 6B). Because TFP-defective mutant strains are expected to lose the ability to contact host cells either wholly or in part, the mutants might have reduced intercellular cAMP levels and expressions of hrp-related genes. Thus, the function of TFP and HR might be regulated by Vfr or some functionally similar factors in this bacterium. Recently, it was revealed that intracellular cAMP levels were reduced by transposon mutagenesis into not only the adenylate cyclase gene $c y a B$ but also $v f r$ and TFP biogenesis genes such as pilA and chpA in $P$. aeruginosa (Fulcher et al. 2010). These results indicate that there is a global regulatory system between cAMP, Vfr, and TFP in controlling virulence. Further investigation to elucidate the involvement of TFP in the regulation of T3SS-mediated HR is necessary, and generation of an $v f r$ mutant strain is now underway.

Although the mechanism of increased tolerance to antimicrobial compounds in the TFP-related mutant strains has not been elucidated yet, the expressions of genes related to multidrug efflux pumps mexA, mexB, and $o p r M$ were significantly elevated in these mutants (Fig. 6). Recently, it was reported that mexAB-oprM-deficient mutants of $P$. syringae pvs. syringae $\mathrm{B} 728 \mathrm{a}$, tomato DC3000, and phaseolicola 1448A showed significantly reduced tolerance to many antimicrobial compounds (Stoitsova et al. 2008). We previously demonstrated that flagellum-mediated motility-defective mutants and AHL production-defective mutants highly express the genes encoding MexE, MexF, and OprN, members of another RND pump family, and exhibit higher tolerance to antibiotics, indicating that flagellum-dependent motility might be correlated with 
quorum sensing and antibiotic tolerance (Taguchi et al. 2010a and b). In TFP-related mutant strains, expression levels of $\operatorname{mexE}, \operatorname{mexF}$, and oprN genes were similar to that of the WT strain (data not shown). Therefore, TFP-mediated expression of mexA, mexB, and oprM and multidrug resistance are not under the control of the quorum sensing by AHL. Very recently, it was reported that expression of cupC and mexAB-oprM genes as well as genes encoding the components of pili and RND pump family in $P$. aeruginosa are controlled under twocomponent regulatory systems. The sensor proteins RocS1 and RocS2 positively regulate cupC gene expression via response regulator RocA1, whereas they negatively regulate mex $A B$ oprM genes via another response regulator, RocA2 (Sivaneson et al. 2011). Therefore, the Roc systems might sense environmental signals and antagonistically control pili formation and antibiotic resistance. Because corresponding orthologs for the components of Roc systems were partly found in $P$. syringae, intricate network for these regulatory systems should be analyzed in phytopathogenic bacteria.

\section{MATERIALS AND METHODS}

Bacterial strains and growth conditions.

All bacterial strains used in this study are listed in Table 3. $P$. syringae pv. tabaci 6605 strains were maintained as described (Naito et al. 2008; Taguchi et al. 2003, 2006b). E. coli strains were grown at $37^{\circ} \mathrm{C}$ in Luria-Bertani (LB) medium. $C$. violaceum $\mathrm{CV} 026$ was grown at $30^{\circ} \mathrm{C}$ in $\mathrm{LB}$ with a final concentration of kanamycin at $50 \mu \mathrm{g} / \mathrm{ml}$.

\section{Plant materials, inoculation procedure, and bacterial growth.}

Tobacco plants (Nicotiana tabacum L. cv. Xanthi NC) were grown at $25^{\circ} \mathrm{C}$ with a 12 -h photoperiod and used for the virulence assay. For dip inoculation of tobacco leaves, overnightcultured bacteria were suspended in $10 \mathrm{mM} \mathrm{MgSO}_{4}$ with $0.02 \%$ Silwet (OSI Specialties, Danbury, CT, U.S.A.) at a density of $2 \times 10^{8} \mathrm{CFU} / \mathrm{ml}$, and detached leaves at the petiole (three leaves for each strain) were dipped in the suspension for $20 \mathrm{~min}$. Then, the leaves were incubated under conditions of $100 \%$ humidity for 1 day and $85 \%$ humidity for 11 subsequent days at $23^{\circ} \mathrm{C}$ with an 18 -h photoperiod and water supply. To examine the bacterial growth, five leaf disks $(8 \mathrm{~mm}$ in diameter) were dip-inoculated in a bacterial suspension in $10 \mathrm{mM}$ $\mathrm{MgSO}_{4}$ with $0.02 \%$ Silwet at a density of $2 \times 10^{8} \mathrm{CFU} / \mathrm{ml}$ for $20 \mathrm{~min}$. For the infiltration experiment, leaves (three leaves for each strain) were infiltrated with bacterial suspension in 10 $\mathrm{mM} \mathrm{MgSO}_{4}$ without Silwet at a density of $4 \times 10^{5} \mathrm{CFU} / \mathrm{ml}$. The leaves were incubated as in the dip inoculation; then, we examined the virulence in symptom severity and bacterial growth. To measure bacterial populations, infiltrated leaves or dip-inoculated leaf disks were soaked in $15 \% \mathrm{H}_{2} \mathrm{O}_{2}$ for $1 \mathrm{~min}$ to sterilize the leaf surfaces and washed with sterile distilled water. Then, 5 dip-inoculated leaf disks or 5 leaf disks punched out from infiltrated leaves were ground with a mortar and pestle. The homogenates in $10 \mathrm{mM} \mathrm{MgSO}_{4}$ were plated on $\mathrm{KB}$ plates after serial dilutions. After a 48-h incubation at $27^{\circ} \mathrm{C}$, the numbers of colonies were counted, and bacterial populations were calculated.

Arabidopsis thaliana ecotype Columbia-0 WT was grown at $22^{\circ} \mathrm{C}$ with a 16 -h photoperiod and was used for the experiments. For the experiment of bacterial growth, overnight-cultured bacteria were suspended in $10 \mathrm{mM} \mathrm{MgSO}_{4}$ with $0.02 \%$ Silwet at a density of $2 \times 10^{8} \mathrm{CFU} / \mathrm{ml}$, and detached leaves (three leaves for each strain) were dipped in the bacterial suspension for $20 \mathrm{~min}$. The bacterial population was measured by the same method for tobacco leaves as that described above. To detect HR induction and callose deposition, Arabidopsis leaves (three leaves for each strain) were infiltrated with bacterial suspension in $10 \mathrm{mM} \mathrm{MgSO}_{4}$ without Silwet at a density of $2 \times 10^{8} \mathrm{CFU} / \mathrm{ml}$.

\section{Construction of mutants and respective complements.}

To generate defective mutants of TFP-related genes (pilA, pilO, fimU, and fimT), genetic regions, including pilA $(1,650$ $\mathrm{bp})$, pilO (2,549 bp), fimU (1,877 bp), and fimT (1,900 bp),

Table 3. Bacterial strains and plasmids

\begin{tabular}{|c|c|c|}
\hline Bacterial strain, plasmid & Relevant characteristics $^{\mathbf{a}}$ & Reference or source \\
\hline \multicolumn{3}{|l|}{ Escherichia coli } \\
\hline DH5 $\alpha$ & $\begin{array}{l}F^{-} \lambda^{-} \phi 80 d L a c Z \Delta M 15 \Delta(\text { lacZYA-argF }) U 169 \text { recAl endA1 hsdR17 }\left(r_{K}^{-} m_{K}^{+}\right) \text {supE44 thi-1 } \\
\text { gyrA relA1 }\end{array}$ & Takara, Kyoto, Japan \\
\hline S17-1 & thi pro $h s d R$ hsdR hsdM+ recA(chr::RP4-2-Tc::Mu-Km::Tn7) & Schäfer et al. 1994 \\
\hline \multicolumn{3}{|l|}{ Chromobacterium violaceum } \\
\hline CV026 & $\begin{array}{l}\text { Double mini-Tn5 mutant from } C \text {. violaceum ATCC31532, acylhomoserine lactone } \\
\text { biosensor }\end{array}$ & McClean et al. 1997 \\
\hline \multicolumn{3}{|l|}{ Pseudomonas syringae pv. tabaci } \\
\hline Isolate 6605 & Wild type isolated from tobacco, $\mathrm{Nal}^{\mathrm{r}}$ & Shimizu et al. 2003 \\
\hline 6605-pilA & Isolate 6605 pilA, $\mathrm{Nal}^{\mathrm{r}}$ & This study \\
\hline 6605-pilO & Isolate 6605 pilO, $\mathrm{Nal}^{\mathrm{r}}$ & This study \\
\hline 6605-fimU & Isolate $6605 \mathrm{fimU}, \mathrm{Nal}^{\mathrm{r}}$ & This study \\
\hline 6605-fimT & Isolate $6605 \mathrm{fim}^{\mathrm{T}}, \mathrm{Nal}^{\mathrm{r}}$ & This study \\
\hline 6605-fliC & Isolate $6605 \mathrm{fliC}, \mathrm{Nal}^{\mathrm{r}}$ & Shimizu et al. 2003 \\
\hline 6605-pilA (pBSL118 pilA) & Isolate 6605 pilA, $\mathrm{Nal}^{\mathrm{r}}$ (pBSL118 pilA) & This study \\
\hline 6605-pilO (pBSL118 pilO) & Isolate 6605 pilO, $\mathrm{Nal}^{\mathrm{r}}$ (pBSL118 pilO) & This study \\
\hline 6605-fimU (pBSL118 fimU) & Isolate 6605 fimU, $\mathrm{Nal}^{\mathrm{r}}$ (pBSL118 fimU) & This study \\
\hline 6605-fimT (pBSL118 fimT) & Isolate 6605 fim, $\mathrm{Nal}^{\mathrm{r}}$ (pBSL118 fimT) & This study \\
\hline \multicolumn{3}{|l|}{ Plasmids } \\
\hline pGEM-TEasy & Cloning vector, $\mathrm{Amp}^{\mathrm{r}}$ & Promega, Tokyo \\
\hline pK18mobSacB & Small mobilizable vector, $\mathrm{Km}^{\mathrm{r}}$, sucrose sensitive ( $\operatorname{sac\mathrm {B}}$ ) & Schäfer et al. 1994 \\
\hline pCR-BluntII-TOPO & Cloning vector, $\mathrm{Km}^{\mathrm{r}}$ & Invitrogen \\
\hline pBSL118 & Mini-Tn5 derived plasmid vector for insertion mutagenesis, $\mathrm{Amp}^{\mathrm{r}}, \mathrm{Km}^{\mathrm{r}}$ & Alexeyev et al. 1995 \\
\hline pBSL-pilA & pilA-containing 1,650-bp DNA fragment in pBSL118 & This study \\
\hline pBSL-pilO & pilO-containing 2,549-bp DNA fragment in pBSL118 & This study \\
\hline pBSL-fimU & fim $U$-containing 1,877 -bp DNA fragment in pBSL1 18 & This study \\
\hline pBSL-fimT & fimT-containing 1,900-bp DNA fragment in pBSL1 18 & This study \\
\hline
\end{tabular}

${ }^{\mathrm{a}} \mathrm{Nal}^{\mathrm{r}}$, nalidixic acid resistant; $\mathrm{Amp}^{\mathrm{r}}$, ampicillin resistant; and $\mathrm{Km}^{\mathrm{r}}$, kanamycin resistant. 
were isolated by pGEM-T-Easy vector cloning systems (Promega Corp., Madison, WI, U.S.A.) using four sets of PCR primers (PilAF: 5'-GTCAGCGTCACTCTGAGTAG-3', PilAR: 5'-GGTCAGTAGTAGCGGCAGTA-3'; (PilOF: 5'-GCTGAC TGACGAAATCCAGC-3', PilOR: 5'-CTGACCGATAACCAC GTAAA-3'; FimUF: 5'-GTCGCGAGGAGAACATCACG-3', FimUR: 5'-ATACCCGTCATCCGGATTTC-3'; and FimTF: 5'AGCAGGCCTATAGCCAGGAT-3', FimTR: 5'-GGCCGTGG CCTGAAAGTATT-3'), which were basically designed based on the registered sequences of each gene of $P$. syringae pv. phaseolicola 1448A (accession number, NC_005773) (Fig. 1). All sequences of amplified DNA fragments were confirmed by ABI PRISM 310 (Applied Biosystems, Chiba, Japan) using a BIG Dye terminator cycle sequencing kit. Digestion was performed with $N h e \mathrm{I}$ and $B s r \mathrm{GI}$ for pilA, AgeI and StuI for pilO, $A v a \mathrm{I}$ for fimU, and $B s s \mathrm{HII}$ and $B s r \mathrm{BI}$ for fimT; this process deleted 246, 437, 314, and $166 \mathrm{bp}$, respectively, of the internal region for generation of the mutant plasmids. After digestion, each purified plasmid was treated with DNA polymerase ( $P y$ robest DNA polymerase; TaKaRa, Otsu, Japan) to generate a blunt-end DNA fragment and self-ligated by DNA ligase (Ligation-Convenience kit; Nippon Gene, Tokyo). The internally deleted DNA fragment was excised from each resulting pGEM plasmid using EcoRI, and introduced into an EcoRI site of pK18mobsacB plasmid (Schäfer et al. 1994). Deletion mutant strains were obtained by conjugation and homologous recombination according to the methods previously reported (Taguchi et al. 2006b).

For complementation of mutants, the constructs described above were used for pilA, fimU, or fimT because each region contains the predicted promoter and entire open reading frame. For complementation of the pilO gene, a set of primers (PilO1: 5'-GTGTTCGAACTCTTTCAGTAA-3', PilOR) was used to clone a 4,961-bp region containing the predicted promoter region and entire open reading frames for pilM to pilP. They were inserted into the EcoRI sites of pBSL118, a transposon vector (Alexeyev et al. 1995), to generate pBSLpilA, pBSLpilO, pBSLfimU, and pBSLfimT, respectively, and were introduced into each respective mutant by conjugation using the E. coli $\mathrm{S} 17-1 \lambda$ pir strain to generate pilA-C, pilO-C, fimU$\mathrm{C}$, or fimT-C.

\section{Motility assay.}

Bacteria cultured overnight in LB medium containing 10 $\mathrm{mM} \mathrm{MgCl} 2$ at $25^{\circ} \mathrm{C}$ were resuspended in $10 \mathrm{mM} \mathrm{MgSO}_{4}$ and adjusted to an optical density at $600 \mathrm{~nm}\left(\mathrm{OD}_{600}\right)$ of 0.3 . For assessment of surface motilities on semisolid agar medium, 3$\mu \mathrm{l}$ aliquots were inoculated in the center of $0.25 \%$ agar MMMF plates $(50 \mathrm{mM}$ potassium phosphate buffer, $7.6 \mathrm{mM}$ $\left[\mathrm{NH}_{4}\right]_{2} \mathrm{SO}_{4}, 1.7 \mathrm{mM} \mathrm{MgCl}$, and $1.7 \mathrm{mM} \mathrm{NaCl}, \mathrm{pH}$ 5.7, supplemented with $10 \mathrm{mM}$ each mannitol and fructose) for the swimming assay and of $0.5 \%$ agar SWM plates $(0.5 \%$ peptone and $0.3 \%$ yeast extract) for the swarming assay (Taguchi et al. $2006 \mathrm{~b}, 2010 \mathrm{~b})$. The motility was examined using three plates for each strain. The surface motility was observed after 48,72 , and $98 \mathrm{~h}$ of incubation at $25^{\circ} \mathrm{C}$. The diameters of the swimming and swarming areas were measured after inoculation for $48 \mathrm{~h}$ at $27^{\circ} \mathrm{C}$. The swimming motility in a liquid MMMF medium was observed by using a phase-contrast microscope.

For the twitching motility assay, the WT and each mutant strain was stab inoculated with a sterile toothpick into the bottom of $1 \%$ agar $\mathrm{KB}$ plates and incubated for $48 \mathrm{~h}$ at $27^{\circ} \mathrm{C}$. After removing the agar, adherent bacteria were stained by $0.5 \%$ crystal violet for $10 \mathrm{~min}$ and washed with water. The areas of the visualized twitching zones of each strain were compared (Giltner et al. 2010). As an alternative method, twitching motility was also assessed by detection of the formation of a light halo around the single colony under light microscopy, according to the method used in Acidovorax avenae subsp. citrulli (Bahar et al. 2009).

\section{Biofilm formation.}

Each bacterial strain was grown in KB medium and the concentration was adjusted to an $\mathrm{OD}_{600}$ of 0.1 with $3 \mathrm{ml}$ of fresh MMMF medium in a polystyrene tube (three tubes for each strain). After a 48 -h incubation at $27^{\circ} \mathrm{C}$ without agitation, adherent bacteria were stained with $0.5 \%$ crystal violet for $1 \mathrm{~h}$ and loosely bound bacteria were removed by washing with $\mathrm{dH}_{2} \mathrm{O}$ three times. For quantitative analysis of biofilms, crystal violet was extracted from stained cells by $3 \mathrm{ml}$ of $95 \%$ ethanol, and $\mathrm{OD}_{595}$ values were measured (Li et al. 2007; Taguchi et al. 2006b).

\section{MIC of antimicrobial compounds.}

Each bacterial strain was grown in KB liquid medium for 24 $\mathrm{h}$, and the concentration was adjusted to a density of $2 \times 10^{5}$ $\mathrm{CFU} / \mathrm{ml}$. The antimicrobial susceptibility test was carried out using chloramphenicol, cefotaxime, ampicillin, spectinomycin, tetracycline, crystal violet, and SDS by a twofold serial dilution on a KB agar plate. The MIC of antimicrobial reagents was determined in triplicate by measuring the growth of each bacterium on $\mathrm{KB}$ agar plates after a 48 -h incubation according to the previously described method (Stoitsova et al. 2008).

\section{RNA preparation, quantitative real-time RT-PCR, and microarray analyses.}

Each bacterial strain was grown in LB medium with $10 \mathrm{mM}$ $\mathrm{MgCl}_{2}$ at $27^{\circ} \mathrm{C}$ to an $\mathrm{OD}_{600}$ of 0.3 . After centrifugation, cells were further incubated in MMMF medium or new LB medium with $10 \mathrm{mM} \mathrm{MgCl}$ as control from an $\mathrm{OD}_{600}$ of 0.3 for $1 \mathrm{~h}$. Then, total RNA was extracted using a High Pure RNA isolation kit (Roche, Mannheim, Germany) according to the manufacturer's instructions. Total RNA $(20 \mu \mathrm{g})$ was used for microarray analyses. Roche NimbleGen microarray analysis was performed using the genome sequence for $P$. syringae pv. phaseolicola 1448A provided by the National Center for Biotechnology Information. This microarray carries 5,172 genes with $6 \times 2$ probes consisting of 60 -mer synthetic oligonucleotides for each gene. All analyses, including normalization by Robust Multichip Average, were performed by NimbleGen Systems. The data obtained was analyzed using NANDEMO Analysis 1.0.2 software (Roche). A $t$ test was applied to the signal intensities of the WT and each mutant, and $P<0.05$ was considered statistically significant.

Total RNA $(2 \mu \mathrm{g})$ was used to synthesize the first-strand cDNA according to the manufacturer's instructions (TaKaRa) in $30 \mu \mathrm{l}$ of a reaction mixture containing $5 \mathrm{U}$ of AMV RTase, $2.5 \mathrm{mM}$ each dNTP, $1 \mu \mathrm{g}$ of random hexamer primer (Roche), $40 \mathrm{U}$ of ribonuclease inhibitor (Takara), $25 \mathrm{mM}$ Tris- $\mathrm{HCl}(\mathrm{pH}$ 8.3), $50 \mathrm{mM} \mathrm{KCl}, 5 \mathrm{mM} \mathrm{MgCl} 2$, and $2 \mathrm{mM}$ dithiothreitol. Obtained first-strand cDNA solution was diluted with four volumes of $\mathrm{dH}_{2} \mathrm{O}$. Specific primers sets for $\operatorname{mexB}$ (mexB-F: 5'TCGACCCATTTTTGCCTGGG-3', mexB-R: 5'-CGAACCG AACACCTTGGAAGT-3'), oprM (oprM-F: 5'-GTCCACGTA GATTGGGTCGA-3', oprM-R: 5'-GAAACACCGACTTCATT GCT-3'), hrpA (hrpA-F: 5'-TGAGTTCTCTGACTAACGCG-3', hrpA-R: 5'-GAAATCAGAACTGGACGACC-3') hrpK (hrpKF: 5'-AGCATCGTGAATCAACCCAC-3', hrpK-R: 5'-GAGTA TTCGGAGTTGTCGAG-3'), and rpoD (rpoD-F: 5'-GATCGT CTCGATCATGTGCA-3', rpoD-R: 5'-ATTGGTCGTCTGCA GCCTGA-3') were designed based on the sequence of $P$. syringae pv. phaseolicola 1448A. Quantitative real-time RT-PCR was carried out using a Rotor-Gene 300 (Corbett Research, Sydney, Australia) and SYBR premix Ex Taq (Perfect Real 
Time, $2 \times$ concentration) (TaKaRa) with primers at final concentrations of $0.2 \mu \mathrm{M}$ each and $1 \mu \mathrm{l}$ of diluted cDNA as template in a $25-\mu$ reaction mixture. The PCR was performed with one denaturation cycle of $10 \mathrm{~s}$ at $95^{\circ} \mathrm{C}$ and 40 cycles of $15 \mathrm{~s}$ at $55^{\circ} \mathrm{C}, 30 \mathrm{~s}$ at $72^{\circ} \mathrm{C}$, and $10 \mathrm{~s}$ at $95^{\circ} \mathrm{C}$. The change of mRNA expression was normalized by $r p o D$, which encodes RNA polymerase sigma factor as a housekeeping gene (Savli et al. 2003). The data were analyzed using the cycle threshold $(\triangle \Delta C T)$ method. Melting curve analysis confirmed that each PCR amplified a single product.

\section{Western blot analysis.}

SDS-PAGE and Western blot analysis were carried out as described previously (Taguchi et al. 2006b; Takeuchi et al. 2003). An overnight culture of each bacterium in KB plates at $27^{\circ} \mathrm{C}$ was harvested, and whole-cell lysates were separated on a $15 \%$ SDS-PAGE gel. After transfer to a polyvinylidene difluoride membrane (Amersham Pharmacia Biotech, Buckinghamshire, U.K.), Western blot analysis was performed using a rabbit polyclonal anti-PilA-specific peptide antibody with a goat anti-rabbit secondary antibody conjugated with alkaline phosphatase (Bio-Rad, Hercules, CA, U.S.A.) and an alkaline phosphatase-based chemiluminescent detection system (CDPStar Reagent, New England Biolabs, Ipswich, MA, U.S.A.) according to the manufacturer's instructions. The synthetic peptide (peptide sequence: VAENYSNGSAQADVC) (Fig. 1B) and the peptide antibody were generated by Operon Biotechnologies (Tokyo) and the serum from the rabbit was collected 42 days after the initial immunization. The polyclonal antibody was affinity purified from $10 \mathrm{ml}$ of antiserum. The antiPilA-specific peptide antibody was used after 5,000-fold dilution with phosphate-buffered saline Tween buffer $(137 \mathrm{mM}$ $\mathrm{NaCl}, 8.1 \mathrm{mM} \mathrm{Na}_{2} \mathrm{HPO}_{4}, 2.68 \mathrm{mM} \mathrm{KCl}, 1.47 \mathrm{mM} \mathrm{KH}{ }_{2} \mathrm{PO}_{4}$, and Tween 20, $\mathrm{pH} 7.4$ ).

\section{Preparation of pilus-containing surface fraction.}

Pili were partially purified as described previously (Smedley et al. 2005), with a minor modification. Each bacterium was grown on $\mathrm{KB}$ plates for $48 \mathrm{~h}$ at $27^{\circ} \mathrm{C}$. Cells were scraped off and resuspended in phosphate buffer $(50 \mathrm{mM}$ sodium phosphate, $\mathrm{pH}$ 7.0). Pili were sheared off the cells by stirring for 30 min, and cells were removed by centrifugation at $10,000 \times g$ for $20 \mathrm{~min}$. After filtration of the supernatant through a 0.45 $\mu \mathrm{m}$-pore filter, polyethylene glycol (PEG6000) and $\mathrm{NaCl}$ were added to final concentrations of $4 \%$ and $0.5 \mathrm{M}$, respectively. Pilus-containing fractions were obtained as pellets by centrifugation at $100,000 \times g$ for $30 \mathrm{~min}$, and were resolved in water.

\section{Detection of AHL.}

Extraction and detection of AHL have been described previously (Taguchi et al. 2006a, 2010b). Bacterial strains were grown in $\mathrm{LB}$ medium with $10 \mathrm{mM} \mathrm{MgCl}_{2}$ for $24 \mathrm{~h}$ at $25^{\circ} \mathrm{C}$. AHL were extracted with an equal volume of ethyl acetate from $3 \mathrm{ml}$ of bacterial culture; then, all of the extract was concentrated and applied to $\mathrm{C}_{18}$ reverse-phase thin-layer chromatography plate. Detection of AHL was carried out using $C$. violaceum $\mathrm{CV} 026$ as the biosensor strain. $N$-hexanoyl-L-homoserine lactone and $N$-(3-oxohexanoyl)-L-homoserine lactone were used as standards of AHL. AHL were visualized as violet spots by the induction of violacein production.

\section{Callose deposition assay.}

Each bacterial strain was grown in LB liquid medium with $10 \mathrm{mM} \mathrm{MgCl} 2$ for $24 \mathrm{~h}$, and the concentration was adjusted at a density of $2 \times 10^{8} \mathrm{CFU} / \mathrm{ml}$. Arabidopsis leaves (three leaves for each strain) were infiltrated with bacterial suspensions of WT and each strain, and were incubated for $48 \mathrm{~h}$ at $23^{\circ} \mathrm{C}$. Cal- lose deposition was detected by aniline blue staining as previously described (Naito et al. 2007). For quantitative analysis, the average number of callose deposits was counted.

\section{Statistical analysis.}

The results of the biofilm formation assay, bacterial population in both host tobacco or nonhost Arabidopsis leaves, quantitative real-time RT-PCR, callose deposition assay, and motility assay are expressed as means with standard deviation. Oneway analysis of variance and Tukey's highly significant difference test were performed using KaleidaGraph (version 4.02; Synergy Software, Reading, PA, U.S.A.) for comparison between the quantitative measurements of the WT, mutants, and complemented strains. $P<0.05$ was considered statistically significant.

\section{Nucleotide sequence accession numbers.}

The nucleotide sequences of the pilA, pilO, fimU, and fimT genes have been deposited in the DDBJ, EMBL, and GenBank nucleotide sequence databases under the accession numbers AB571112 to AB571115, respectively.

\section{ACKOWLEDGMENTS}

This work was supported in part by the Program for Promotion of Basic Research Activities for Innovative Bioscience (PROBRAIN). We thank the Leaf Tobacco Research Laboratory of Japan Tobacco Inc. for providing $P$. syringae pv. tabaci 6605 .

\section{LITERATURE CITED}

Alexeyev, M. F., Shokolenko, I. N., and Croughan, T. P. 1995. New miniTn5 derivatives for insertion mutagenesis and genetic engineering in gram-negative bacteria. Can. J. Microbiol. 41:1053-1055.

Alguel, Y., Meng, C., Terán, W., Krell, T., Ramos, J. L., Gallegos, M. T., and Zhang, X. 2007. Crystal structures of multidrug binding protein TtgR in complex with antibiotics and plant antimicrobials. J. Mol. Biol. 369:829-840.

Ayers, M., Sampaleanu, L. M., Tammam, S., Koo, J., Harvey, H., Howell, P. L., and Burrows, L. L. 2009. PilM/N/O/P proteins form an inner membrane complex that affects the stability of the Pseudomonas aeruginosa type IV pilus secretin. J. Mol. Biol. 394:128-142.

Bahar, O., Goffer, T., and Burdman, S. 2009. Type IV pili are required for virulence, twitching motility, and biofilm formation of Acidovorax avenae subsp. citrulli. Mol. Plant-Microbe Interact. 22:909-920.

Bahar, O., De La Fuente, L., and Burdman, S. 2010. Assessing adhesion, biofilm formation and motility of Acidovorax citrulli using microfluidic flow chambers. FEMS (Fed. Eur. Microbiol. Soc.) Microbiol. Lett. 312:33-39.

Fulcher, N. B., Holliday, P. M., Klem, E., Cann, M. J., and Wolfgang, M. C. 2010. The Pseudomonas aeruginosa Chp chemosensory system regulates intracellular cAMP levels by modulating adenylate cyclase activity. Mol. Microbiol. 76:889-904.

Giltner, C. L., Habash, M., and Burrows, L. L. 2010. Pseudomonas aeruginosa minor pilins are incorporated into type IV pili. J. Mol. Biol. 398:444-461.

Ichinose, Y., Shimizu, R., Ikeda, Y., Taguchi, F., Marutani, M., Mukaihara, T., Inagaki, Y., Toyoda, K., and Shiraishi, T. 2003. Need for flagella for complete virulence of Pseudomonas syringae pv. tabaci: Genetic analysis with flagella-defective mutants $\Delta$ fliC and $\Delta$ fliD in host tobacco plants. J. Gen. Plant Pathol. 69:244-249.

Jin, Q., Thilmony, R., Zwiesler-Vollick, J., and He, S.Y. 2003. Type III protein secretion in Pseudomonas syringae. Microbes Infect. 5:301310 .

Kang, Y., Liu, H., Genin, S., Schell, M. A., and Denny, T. P. 2002. Ralstonia solanacearum requires type 4 pili to adhere to multiple surfaces and for natural transformation and virulence. Mol. Microbiol. 46:427437.

Köhler, T., Curty, L. K., Barja, F., van Delden, C., and Pechere, J. C. 2000. Swarming of Pseudomonas aeruginosa is dependent on cell-to-cell signaling and requires flagella and pilli. J. Bacteriol. 182:5990-5996.

Li, Y., Hao, G., Galvani, C. D., Meng, Y., De La Fuente, L., Hoch, H. C., and Burr, T. J. 2007. Type I and type IV pili of Xylella fastidiosa affect twitching motility, biofilm formation and cell-cell aggregation. Microbiology 153:719-726. 
Lindgren, P. B., Peet, R. C., and Panopoulos, N. J. 1986. Gene cluster of Pseudomonas syringae pv. "phaseolicola" controls pathogenicity of bean plants and hypersensitivity of nonhost plants. J. Bacteriol. 168:512-522. Erratum. 1987. J. Bacteriol. 169:928.

Liu, H., Kang, Y., Genin, S., Schell, M. A., and Denny, T. P. 2001 Twitching motility of Ralstonia solanacearum requires a type IV pilus system. Microbiology 147:3215-3229.

Mattick J. S. 2002. Type IV pili and twitching motility. Annu. Rev. Microbiol. 56:289-314.

Mazariego-Espinosa, K., Cruz, A., Ledesma, M. A., Ochoa, S. A., and Xicohtencatl-Cortes, J. 2010. Longus, a type IV pilus of enterotoxigenic Escherichia coli, is involved in adherence to intestinal epithelial cells. J. Bacteriol. 192:2791-2800.

McClean, K. H., Winson, M. K., Fish, L., Taylor, A., Chhabra, S. R., Camara, M., Daykin, M., Lamb, J. H., Swift, S., Bycroft, B. W., Stewart, G. S., and Williams, P. 1997. Quorum sensing and Chromobacterium violaceum: Exploitation of violacein production and inhibition for the detection of N-acylhomoserine lactones. Microbiology 143:3703-3711.

Meng, Y., Li, Y., Galvani, C. D., Hao, G., Turner, J. N., Burr, T. J., and Hoch, H. C. 2005. Upstream migration of Xylella fastidiosa via pilusdriven twitching motility. J. Bacteriol. 187:5560-5567.

Naito, K., Ishiga, Y., Toyoda, K., Shiraishi, T., and Ichinose, Y. 2007. Nterminal domain including conserved flg22 is required for flagellininduced hypersensitive cell death in Arabidopsis thaliana. J. Gen. Plant Pathol. 73:281-285.

Naito, K., Taguchi, F., Suzuki, T., Inagaki, Y., Toyoda, T., Shiraishi, T., and Ichinose, Y. 2008. Amino acid sequence of bacterial microbe-associated molecular pattern flg22 is required for virulence. Mol. Plant-Microbe Interact. 21:1165-1174.

Ojanen-Reuhs, T., Kalkkinen, N., Westerlund-Wikström, B., van Doorn, J., Haahtela, K., Nurmiaho-Lassila, E. L., Wengelnik, K., Bonas, U., and Korhonen, T. K. 1997. Characterization of the fimA gene encoding bundle-forming fimbriae of the plant pathogen Xanthomonas campestris pv. vesicatoria. J. Bacteriol. 179:1280-1290.

Pelicic, V. 2008. Type IV pili: E pluribus unum? Mol. Microbiol. 68:827837.

Proft, T., and Baker, E. N. 2009. Pili in gram-negative and gram-positive bacteria-structure, assembly and their role in disease. Cell. Mol. Life Sci. 66:613-35

Roine, E., Raineri, D. M., Romantschuk, M., Wilson, M., and Nunn, D. N. 1998. Characterization of type IV pilus genes in Pseudomonas syringae pv. tomato DC3000. Mol. Plant-Microbe Interact. 11:1048-1056.

Romantschuk, M., and Bamford, D. H. 1986. The causal agent of halo blight in bean, Pseudomonas syringae pv. phaseolicola, attaches to stomata via its pili. Microb. Pathog. 1:139-148.

Sampaleanu, L. M., Bonanno, J. B., Ayers, M., Koo, J., Tammam, S., Burley, S. K., Almo, S. C., Burrows, L. L., and Howell, P. L. 2009. Periplasmic domains of Pseudomonas aeruginosa PilN and PilO form a stable heterodimeric complex. J. Mol. Biol. 394:143-159.

Savli, H., Karadenizli, A., Kolayli, F., Gundes, S., Ozbek, U., and Vahaboglu, H. 2003. Expression stability of six housekeeping genes: A proposal for resistance gene quantification studies of Pseudomonas aeruginosa by real-time quantitative RT-PCR. J. Med. Microbiol. 52:403-408

Schäfer, A., Tauch, A., Jäger, W., Kalinowski, J., Thierbach, G., and Pühler, A. 1994. Small mobilizable multi-purpose cloning vectors derived from the Escherichia coli plasmids pK18 and pK19: Selection of defined deletions in the chromosome of Corynebacterium glutamicum. Gene 145:69-73.

Shimizu, R., Taguchi, F., Marutani, M., Mukaihara, T., Inagaki, Y., Toyoda, K., Shiraishi, T., and Ichinose, Y. 2003. The $\Delta$ fliD mutant of Pseudomonas syringae pv. tabaci, which secretes flagellin monomers, induces a strong hypersensitive reaction (HR) in non-host tomato cells. Mol. Genet. Genomics 269:21-30.

Sivaneson, M., Mikkelsen, H., Ventre, I., Bordi, C., and Filloux, A. 2011. Two-component regulatory systems in Pseudomonas aeruginosa: An intricate network mediating fimbrial and efflux pump gene expression. Mol. Microbiol. 79:1353-1366.

Smedley, J. G., 3rd, Jewell, E., Roguskie, J., Horzempa, J., Syboldt, A.,
Stolz, D. B., and Castric, P. 2005. Influence of pilin glycosylation on Pseudomonas aeruginosa 1244 pilus function. Infect. Immun. 73:79227931.

Stoitsova, S. O., Braun, Y., Ullrich, M. S., and Weingart, H. 2008. Characterization of the RND-type multidrug efflux pump MexAB-OprM of the plant pathogen Pseudomonas syringae. Appl. Environ. Microbiol. 74:3387-3393

Strom, M. S., Nunn, D. N., and Lory, S. 1993. A single bifunctional enzyme, PilD, catalyzes cleavage and N-methylation of proteins belonging to the type IV pilin family. Proc. Natl. Acad. Sci. U.S.A. 90:2404-2408.

Taguchi, F., Shimizu, R., Inagaki, Y., Toyoda, K., Shiraishi, T., and Ichinose, Y. 2003a. Post-translational modification of flagellin determines the specificity of HR induction. Plant Cell Physiol. 44:342-349.

Taguchi, F., Shimizu, R., Nakajima, R., Toyoda, K., Shiraishi, T., and Ichinose, Y. 2003b. Differential effects of flagellins from Pseudomonas syringae pv. tabaci, tomato and glycinea on plant defense response. Plant Physiol. Biochem. 41:165-174.

Taguchi, F., Ogawa, Y., Takeuchi, K., Suzuki, T., Toyoda, K., Shiraishi, T., and Ichinose, Y. 2006a. A homologue of the 3-oxoacyl-(acyl carrier protein) synthase III gene located in the glycosylation island of Pseudomonas syringae pv. tabaci regulates virulence factors via $\mathrm{N}$-acyl homoserine lactone and fatty acid synthesis. J. Bacteriol. 188:83768384

Taguchi, F., Takeuchi, K., Katoh, E., Murata, K., Suzuki, T., Marutani, M. Kawasaki, T., Eguchi, M., Katoh, S., Kaku, H., Yasuda, C., Inagaki, Y., Toyoda, K., Shiraishi, T., and Ichinose, Y. 2006b. Identification of glycosylation genes and glycosylated amino acids of flagellin in Pseudomonas syringae pv. tabaci. Cell. Microbiol. 8:923-938.

Taguchi, F., Shibata, S., Suzuki, T., Ogawa, Y., Aizawa, S., Takeuchi, K., and Ichinose, Y. 2008. Effects of glycosylation on swimming ability and flagellar polymorphic transformation in Pseudomonas syringae pv. tabaci 6605. J. Bacteriol. 190:764-768.

Taguchi, F., Suzuki, T., Inagaki, Y., Toyoda, K., Shiraishi, T., and Ichinose, Y. 2010a. The siderophore pyoverdine of Pseudomonas syringae pv. tabaci 6605 is an intrinsic virulence factor in host tobacco infection. J. Bacteriol. 192:117-126.

Taguchi, F., Yamamoto, M., Ohnishi-Kameyama, M., Iwaki, M., Yoshida, M., Ishii, T., Konishi, T., and Ichinose, Y. 2010b. Defects in flagellin glycosylation affect the virulence of Pseudomonas syringae pv. tabaci 6605. Microbiology 156:72-80.

Takeuchi, K., Taguchi, F., Inagaki, Y., Toyoda, K., Shiraishi, T., and Ichinose, Y. 2003. Flagellin glycosylation island in Pseudomonas syringae pv. glycinea and its role in host specificity. J. Bacteriol. 185:6658 6665.

Terán, W., Krell, T., Ramos, J. L., and Gallegos, M. T. 2006. Effector-repressor interactions, binding of a single effector molecule to the operatorbound TtgR homodimer mediates derepression. J. Biol. Chem. 281:7102 7109

Wang, L., Makino, S., Subedee, A., and Bogdanove, A. J. 2007. Novel candidate virulence factors in rice pathogen Xanthomonas oryzae pv. oryzicola as revealed by mutational analysis. Appl. Environ. Microbiol. 73:8023-8027.

Whitchurch, C. B., Beatson, S. A., Comolli, J. C., Jakobsen, T., Sargent, J. L., Bertrand, J. J., West, J., Klausen, M., Waite, L. L., Kang, P. J., Tolker-Nielsen, T., Mattick, J. S., and Engel, J. N. 2005. Pseudomonas aeruginosa fimL regulates multiple virulence functions by intersecting with Vfr-modulated pathways. Mol. Microbiol. 55:1357-1378.

Wolfgang, M. C., Lee, V. T., Gilmore, M. E., and Lory, S. 2003. Coordinate regulation of bacterial virulence genes by a novel adenylate cyclase-dependent signaling pathway. Dev. Cell 4:253-263.

Yahr, T. L., and Wolfgang, M. C. 2006. Transcriptional regulation of the Pseudomonas aeruginosa type III secretion system. Mol. Microbiol. 62:631-640.

\section{AUTHOR-RECOMMENDED INTERNET RESOURCE}

Pseudomonas Genome database v2: v2.pseudomonas.com 